\author{
EVS29 Symposium \\ Montréal, Québec, Canada, \\ June 19-22, 2016
}

\title{
Plug-in Vehicle Behaviors: An analysis of charging and driving behavior of Ford plug-in electric vehicles in the real world
}

\author{
Daniel Boston ${ }^{1}$, Alyssa Werthman ${ }^{1}$ \\ ${ }^{1}$ Ford Motor Company, 1 American Road, Dearborn MI, dboston8@ford.com
}

\begin{abstract}
Summary
This paper analyzes the charging and driving behavior collected from thousands of North American Ford full battery electric vehicles (BEVs) and plug-in hybrid electric vehicles (PHEVs) whose owners utilize the MyFord Mobile smart phone app, thus enabling aggregated data for analysis. The trends investigated include charging frequency, electric vehicle miles travelled (eVMT), daily miles driven, and other factors.
\end{abstract}

Keywords: charging, data acquisition, North America, PHEV, case study

\section{Introduction}

The recent increase in the number of electrified vehicles offered presents drivers the option of choosing electrical or conventional gasoline energy sources. A current full battery electric vehicle has a reduced range compared to a conventional vehicle, and requires more attention to route planning and battery charging. This paper analyzes plug-in electric vehicle usage patterns and charging behavior, and indicates additional information that may be needed to understand the impact electrification has on the vehicle ownership experience.

The plug-in vehicle data set analyzed was collected from thousands of North American Ford full battery electric vehicles (BEV) and plug-in hybrid electric vehicles (PHEV) whose owners opted in to aggregate data collection using the MyFord Mobile smart phone app. Actuation data is transmitted wirelessly at keyon, key-off, and after charging events. The models included are the 2012-2016 Ford Focus Electric, 20132016 Ford Fusion Energi PHEV and 2013-2016 Ford C-MAX Energi PHEV. The data includes battery state of charge, distance driven using gasoline and electricity, energy consumed, and other parameters associated with driving and charging behavior. This data was processed and analyzed to benchmark the performance and characteristics of driving and charging patterns based on model type, geographic location, average daily distances driven and other criteria.

The data set used for this analysis was collected between January $1^{\text {st }} 2013$ and October $15^{\text {th }} 2015$. Ford has shared this data set with the California Air Resources Board (ARB), Idaho National Laboratory (INL), and University of California - Davis (UC-Davis), enabling joint analysis, with the goal of developing a common understanding of plug-in vehicle behavior. This report represents Ford's independent analysis of this data. The vehicles included in this data set consist of 12,429 Fusion Energi vehicles, 10,084 C-MAX Energi vehicles and 4,185 Focus Electric vehicles. The Fusion Energi and C-MAX Energi have an allelectric range (AER) of 19 miles, and can be fully charged on a 240 volt level 2 charger in approximately 2.5 hours, or 7 hours on a 120 volt level 1 charger. The Focus Electric BEV has 76 miles of AER, and can be fully charged in 3.6 hours from a level 2 charger, or approximately 18-20 hours on a level 1 charger. 
Each of these vehicles is delivered with a level 1 convenience charge cord which can charge the vehicle from any standard $120 \mathrm{~V}$ household outlet.

This paper will analyze the charging behavior of the Ford electrified vehicle fleet over a period of nearly three years. In addition to traditional metrics, we will identify how differing geographic areas affect plug-in performance and influence vehicle usage behavior. Data will be presented in summer and winter categories, as seasonal effects are a key influence on geographical differences. The summer season includes months April through September, while the winter season includes months October through March. We will divide the analysis amongst four geographic regions: Canada, California, the Northeast (NE) Zero Emission Vehicle (ZEV) mandate member states, and the United States excluding California and the NE ZEV states. The NE ZEV mandate states include Connecticut, Maine, Maryland, Massachusetts, New Jersey, New York, Rhode Island and Vermont.

A number of studies have analyzed trip characteristics and charging behavior for plug-in vehicles. In particular, the DOE-funded EV Project from Idaho National Laboratory analyzed the charging behavior of a large number of Chevrolet Volts and Nissan Leafs over a three year time period. We will compare our results with this study throughout the paper, as it contains a variety of insights into BEV and PHEV charging and driving behavior with which to benchmark our own fleet.

\section{Trip Based Metrics}

\subsection{Average Trip Length}

Trip data is captured in a trip report, which summarizes information captured between key-on and key-off events, such as total trip distance, EV distance traveled, gasoline consumed, electricity consumed, etc. A valuable parameter to analyze is the average trip length that a customer takes.

Table 1 Average Trip Length (Miles)

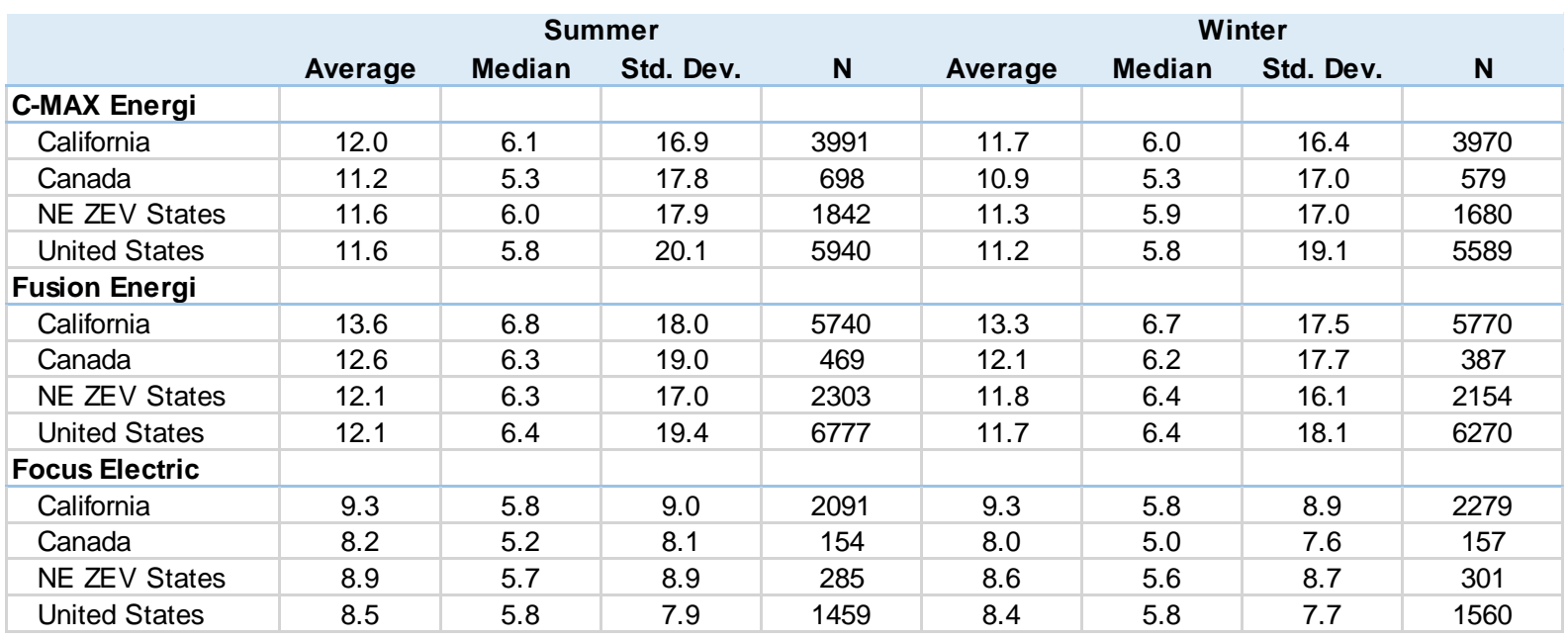

The Ford PHEVs average trip length is consistently between 11 and 13 miles, with a modest rise during the summer months, due to the very long trips which are more frequently taken during the summer. C-MAX Energi vehicles have slightly lower average trip lengths than Fusion Energi vehicles. With combined electric and gas range, the Ford PHEVs are capable of taking trips of over 500 hundred miles, which raises their average trip length. Conversely, the Ford Focus Electric BEV range is 76 miles, leading to mostly shorter trips. This reduces the average trip length driven in comparison to PHEVs; BEVs are not capable of taking very long trips without charging.

\subsection{Distance Traveled Each Day}

The average miles driven per day across all days driven for PHEVs is $45.4, \sigma= \pm 49.2$ with a median of 32.4 miles. The average miles driven per day across all days for BEVs is $31.0, \sigma= \pm 21.7$ with a median of 26.8 miles. BEVs from the EV Project demonstrated a slightly lower 29.5 miles per day, and extended range electric vehicles (EREVs) in the EV Project drove 41 miles per day, compared to this study's 45.4 for PHEVs [1]. 
Table 2 Total Miles Driven Per Day

\begin{tabular}{|c|c|c|c|c|c|c|c|c|}
\hline & \multicolumn{4}{|c|}{ Summer } & \multicolumn{4}{|c|}{ Winter } \\
\hline & Average & Median & Std. Dev. & $\mathbf{N}$ & Average & Median & Std. Dev. & $\mathbf{N}$ \\
\hline \multicolumn{9}{|l|}{ C-MAX Energi } \\
\hline California & 45.2 & 33.3 & 44.1 & 3991 & 43.7 & 32.5 & 42.5 & 3970 \\
\hline Canada & 43.7 & 27.8 & 50.2 & 698 & 40.5 & 26.0 & 46.1 & 579 \\
\hline NE ZEV States & 42.7 & 29.5 & 45.6 & 1842 & 39.7 & 27.3 & 42.5 & 1680 \\
\hline United States & 44.7 & 28.8 & 58.5 & 5940 & 42.2 & 27.6 & 54.7 & 5589 \\
\hline \multicolumn{9}{|l|}{ Fusion Energi } \\
\hline California & 50.3 & 38.7 & 45.7 & 5740 & 48.9 & 37.8 & 44.0 & 5770 \\
\hline Canada & 48.6 & 33.4 & 51.5 & 469 & 44.2 & 30.7 & 46.3 & 387 \\
\hline NE ZEV States & 44.2 & 32.6 & 42.7 & 2303 & 41.4 & 30.4 & 40.0 & 2154 \\
\hline United States & 46.1 & 32.2 & 54.8 & 6777 & 43.4 & 30.9 & 50.1 & 6270 \\
\hline \multicolumn{9}{|l|}{ Focus Electric } \\
\hline California & 31.7 & 27.5 & 22.1 & 2091 & 31.4 & 27.4 & 21.6 & 2279 \\
\hline Canada & 32.8 & 27.8 & 23.4 & 154 & 29.3 & 24.4 & 21.6 & 157 \\
\hline NE ZEV States & 31.7 & 26.8 & 23.1 & 285 & 28.2 & 23.3 & 21.7 & 301 \\
\hline United States & 30.9 & 26.7 & 21.5 & 1459 & 29.3 & 25.3 & 20.3 & 1560 \\
\hline
\end{tabular}

The number of miles driven per day by model for each region and season is illustrated in Table 2. The standard deviation for PHEVs is larger than for BEV vehicles, which is to be expected given the longer drivable range before the vehicle requires refueling. All vehicles exhibit reduced mileage per day during the winter months, with the exception of California vehicles which have a very modest reduction. This is most likely a function of differences in driving habits between regions, and the seasonal effects of weather. One key point to note is that Canadian BEVs travel further per day than BEVs from any other region during the summer. This is most likely an impact of the robust charging infrastructure, which will be addressed later in this report. For reference, all U.S. drivers, both conventional and electrified, average 29.2 miles per day and drive more in the summer than the winter, similar to the Ford electric vehicle drivers [2].

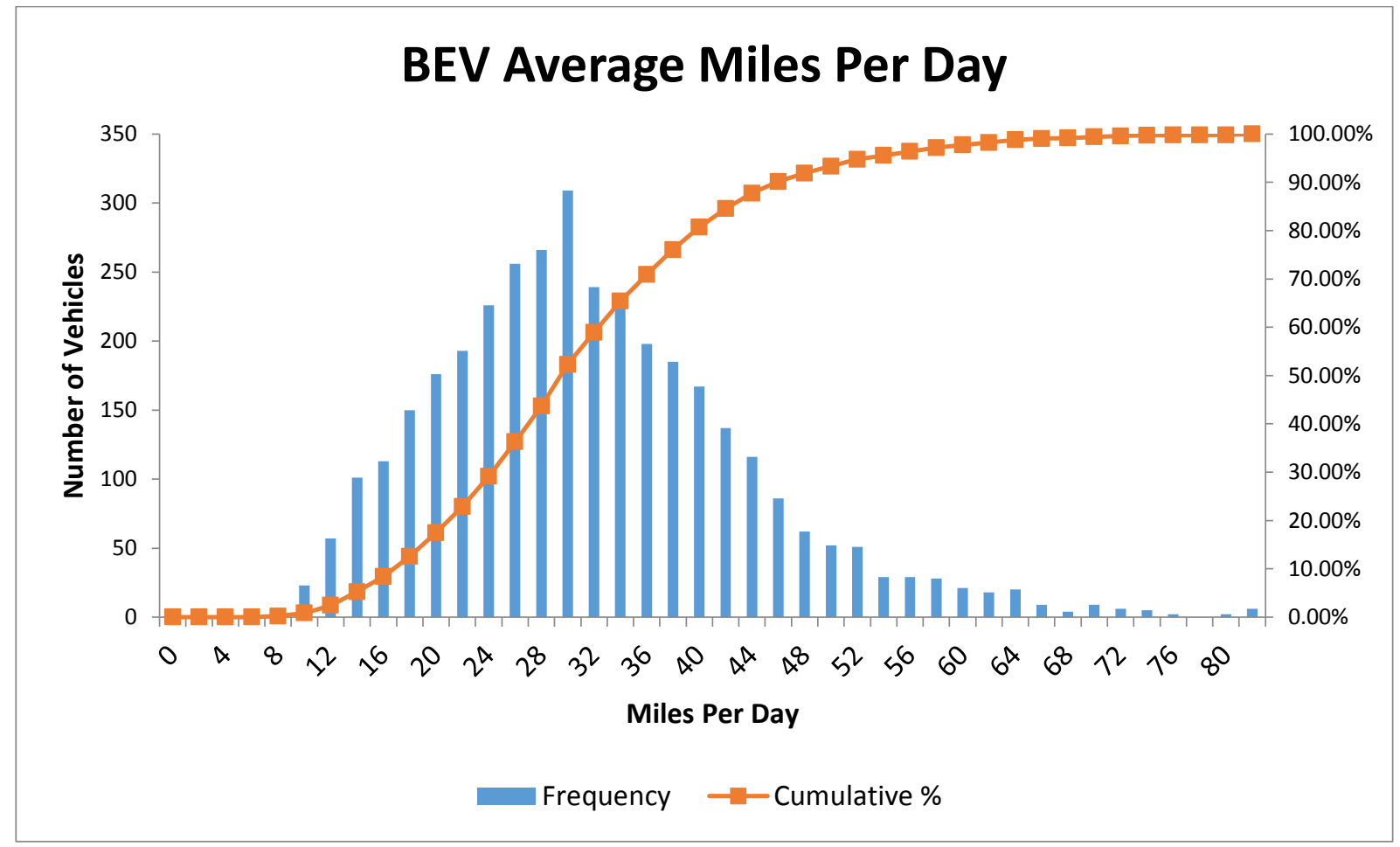

Figure 1 BEV Miles Per Day Distribution

Figure 1 illustrates the distribution of BEV average distance per day. While a Focus BEV has 76 miles of AER, there are some Focus Electric vehicles which exceed this distance on a daily basis. This behavior has also been seen in the EV Project, with $4 \%$ of BEVs requiring workplace charging in order to fulfill their daily driving [1]. 


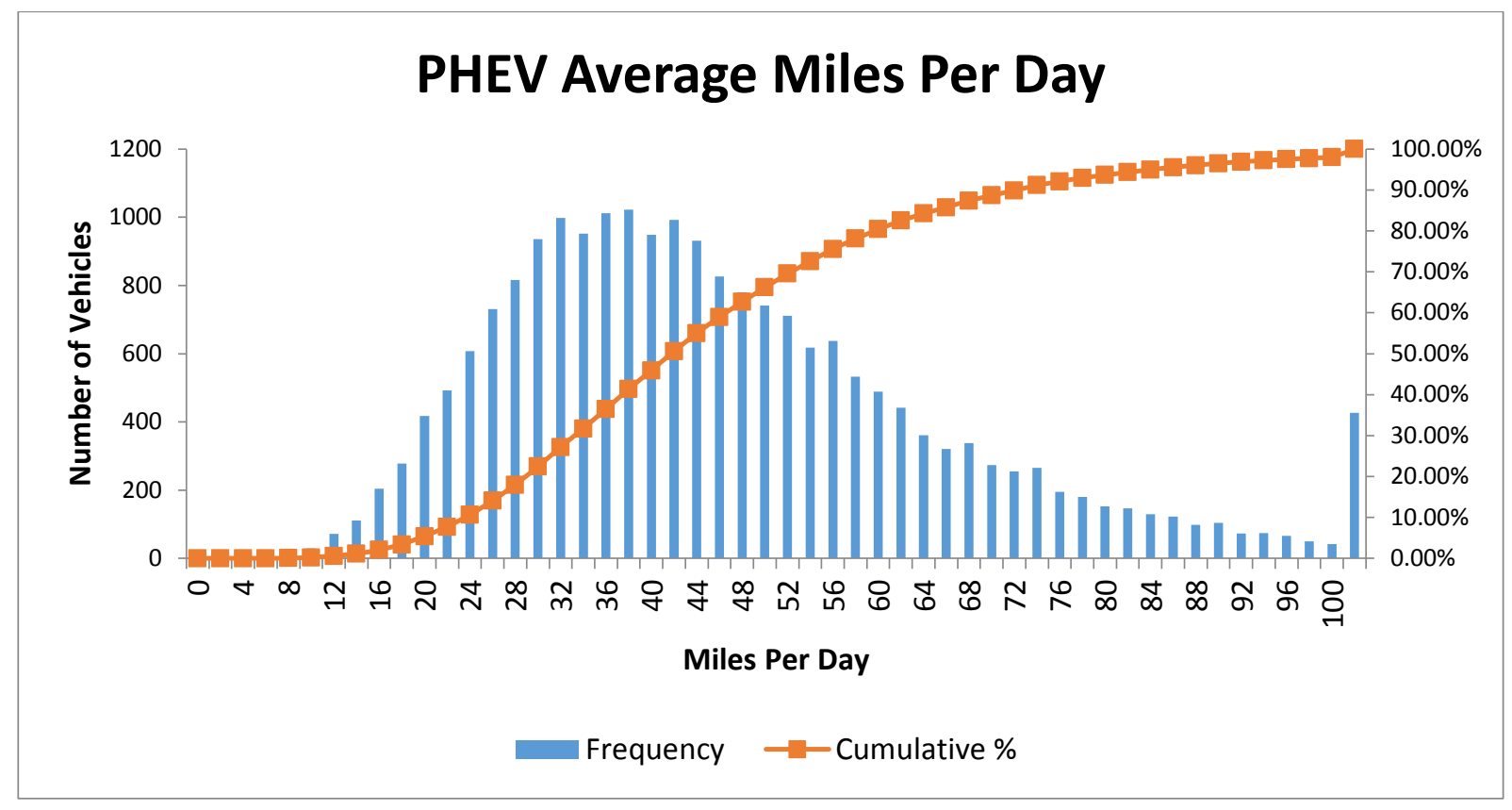

Figure 2 PHEV Miles Per Day Distribution

PHEVs exhibit a wider range of daily mileage than BEVs, as expected, with $10 \%$ of PHEVs driving less than 24 miles per day on average. A population of 427 vehicles out of the 21,016 ( 2\%) analyzed exceed 100 miles per day on average. Our analyses in the past have shown that this behavior is exhibited by fleet customers, who have similar trip lengths to personal vehicles but greatly exceed the number of trips taken in a day compared to personal vehicles.

This behavior of a sizable population achieving high mileage is seen in the PHEVs and not in the BEVs, indicating that PHEVs more adequately satisfy the needs of fleet customers and high mileage retail customers.

\subsection{Electric Vehicle Miles Traveled}

The comparison of electric miles vs gasoline miles driven by PHEVs is a very important metric, and one that depends largely on driver behavior. The electric vehicle miles traveled or eVMT provides an understanding of how many miles a PHEV travels using electricity compared to using gasoline. The equation being used for this paper relies on those electric miles driven as a direct result of the power to charge the vehicle battery from the grid, and does not include power derived from other sources such as brake regeneration. To calculate this we need the total trip length, the gasoline consumed during the trip, the electricity consumed during the trip, and the stated efficiencies of the vehicle.

elecMiles $=\left(\frac{E_{\text {elec }}}{E_{\text {elec }}+\left(\frac{n_{\text {eleclabel }}^{*} \text { charge }_{\text {chas }}}{n_{\text {gas }}}\right) * F_{\text {gas }}}\right) *$ dist

Here $E_{\text {elec }}$ is the DC electricity consumed during a trip in kilowatt hours, $F_{\text {gas }}$ is the amount of gasoline consumed on a trip in gallons, dist is the total trip distance in miles, $n_{\text {eleclabel }}$ is the AC electrical consumption efficiency, ( $37 \mathrm{~kW}-\mathrm{hr} / 100$ miles), $n_{\text {charge }}$ is the battery charging efficiency (0.805), and $n_{\text {gas }}$ is the gasoline consumption efficiency (2.6 gallons /100 miles).

With this information we can calculate the total electrical miles driven for any trip taken. For BEVs the calculation is much simpler with the total eVMT equal to the trip length.

The eVMT \% achieved is the eVMT divided by the total miles driven. It should be noted that this eVMT \% is grid based, meaning only the electricity derived from plugging in is accounted for. When including nongrid based sources, such as brake regeneration, the total EV miles travelled exceeds $50 \%$ on average. 
PHEVs overall average $32.6 \mathrm{eVMT} \%$ in winter months and $34.0 \mathrm{eVMT} \%$ in summer months

Table 3 eVMT \%

\begin{tabular}{|l|c|c|c|c|}
\multicolumn{1}{c}{} & \multicolumn{2}{c}{ Summer } & \multicolumn{2}{c|}{ Winter } \\
\hline C-MAX Energi & eVMT\% & N & eVMT\% & N \\
\hline California & $33.99 \%$ & 3991 & $34.43 \%$ & 3970 \\
\hline Canada & $36.28 \%$ & 698 & $31.26 \%$ & 579 \\
\hline NE ZEV States & $32.62 \%$ & 1842 & $27.71 \%$ & 1680 \\
\hline United States & $34.94 \%$ & 5940 & $32.17 \%$ & 5589 \\
\hline Fusion Energi & & & & \\
\hline California & $31.80 \%$ & 5740 & $32.57 \%$ & 5770 \\
\hline Canada & $36.22 \%$ & 469 & $30.58 \%$ & 387 \\
\hline NE ZEV States & $32.11 \%$ & 2303 & $28.04 \%$ & 2154 \\
\hline United States & $36.42 \%$ & 6777 & $34.42 \%$ & 6270 \\
\hline
\end{tabular}

Table 3 illustrates several trends amongst the different regions. California is the only region which performs better in the winter than in summer. This is due to the increased use of air conditioning in the summer and less need for heating in the winter. The NE ZEV States and Canada both demonstrate decreases in eVMT \% during winter. The NE ZEV states decrease 4-5\% and Canadian vehicles decrease 5-6\% between the summer and winter months. Despite these large decreases, Canadian winter eVMT \% is nearly as large as the summer performance in the NE ZEV states and in California.

Canadian vehicles are driven less than American vehicles and this could have an impact on the eVMT \% seen between the regions. This will be discussed further in section 4.1

\section{Charging Metrics}

\subsection{Charge Events per Week}

One of the primary metrics of charging behavior is the number of charge events performed per week by the vehicle owner. A charge event is initiated when the vehicle begins to accept charge, from either a dedicated charging station, known as electric vehicle service equipment (EVSE), or a standard wall outlet; and ends when the vehicle has fully charged, the user has unplugged the vehicle, or the event has been stopped remotely.

Table 4 Charge Events Per Week

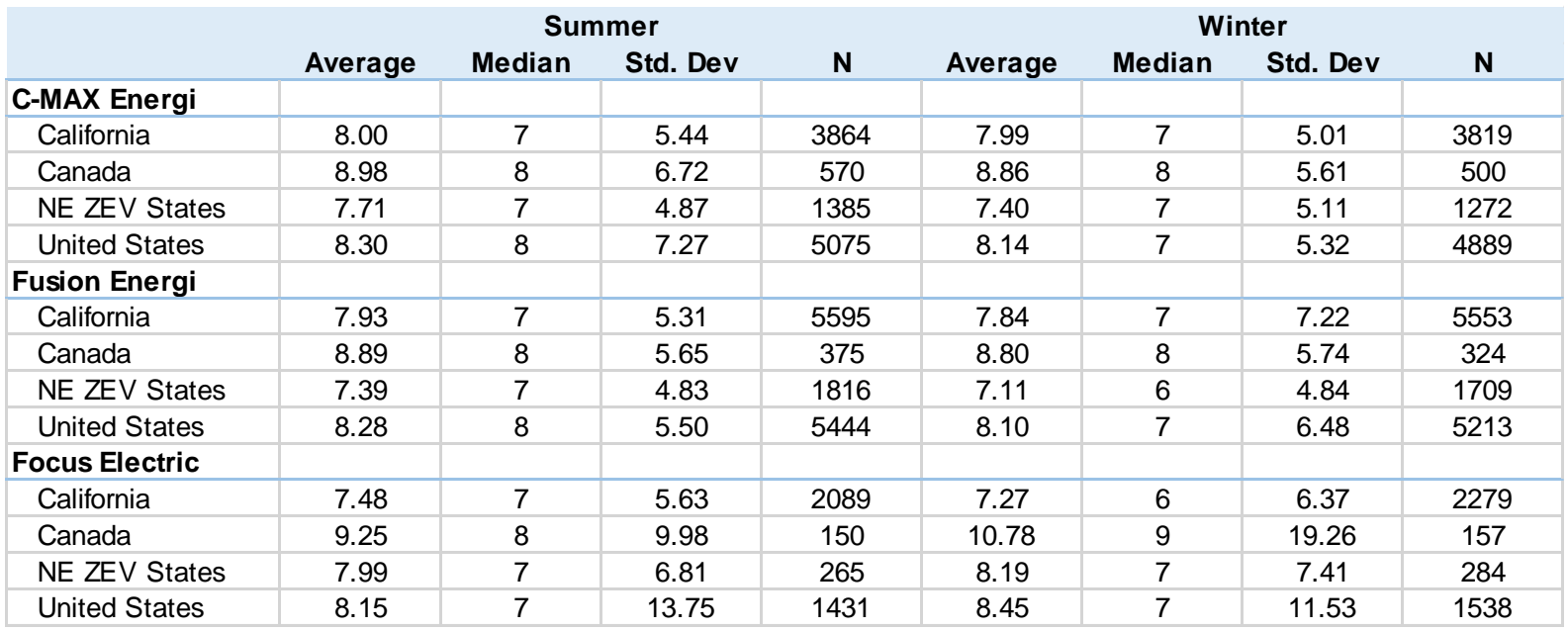

Table 4 demonstrates the differences and similarities amongst regions. One similarity between all regions is the large variation in the standard deviation indicating vehicle owners charge on a broad spectrum. This large standard deviation indicates analyzing the mean and median may not provide sufficient understanding. Nearly all regions exhibit a consistent charging median of once per day. PHEVs appear to charge slightly less during the winter months while the BEV charges slightly more, except for California 
BEVs. This additional charging from BEVs could be out of necessity. As available battery range is reduced in cold temperatures, owners may be charging their vehicles more often to ensure they have sufficient range to reach their final destination.

One anomaly is that the Canadian vehicles charge more often than all of the others, and this is especially seen in BEVs during the winter time. Additional analysis in section 4.2 will investigate the reasoning for this behavior which is unique to Canadian drivers.

\subsection{Charger Types: Level 1 and Level 2}

PHEV and BEV drivers vary significantly in how often they charge their vehicles at level 1 or level 2.

Table 5 Charger Power Type

\begin{tabular}{|c|c|c|c|c|c|c|}
\hline & \multicolumn{2}{c}{ Level 1 } & Level 1 & \multicolumn{2}{c}{ Level 2 } & Level 2 \\
\hline & Summer & Winter & Total & Summer & Winter & Total \\
\hline C-MAX Energi & $\mathbf{4 0 . 4 7 \%}$ & $\mathbf{3 0 . 3 8} \%$ & $\mathbf{7 0 . 8 5 \%}$ & $\mathbf{1 6 . 6 4 \%}$ & $\mathbf{1 2 . 5 2 \%}$ & $\mathbf{2 9 . 1 5 \%}$ \\
\hline California & $41.15 \%$ & $31.70 \%$ & $72.85 \%$ & $15.38 \%$ & $11.76 \%$ & $27.15 \%$ \\
\hline Canada & $29.18 \%$ & $21.22 \%$ & $50.40 \%$ & $28.97 \%$ & $20.64 \%$ & $49.60 \%$ \\
\hline NE ZEV States & $44.00 \%$ & $33.28 \%$ & $77.29 \%$ & $13.29 \%$ & $9.42 \%$ & $22.71 \%$ \\
\hline United States & $40.21 \%$ & $29.58 \%$ & $69.79 \%$ & $17.19 \%$ & $13.02 \%$ & $30.21 \%$ \\
\hline Fusion Energi & $\mathbf{4 3 . 2 8} \%$ & $\mathbf{3 1 . 2 6} \%$ & $\mathbf{7 4 . 5 4 \%}$ & $\mathbf{1 4 . 7 9} \%$ & $\mathbf{1 0 . 6 7 \%}$ & $\mathbf{2 5 . 4 6 \%}$ \\
\hline California & $43.86 \%$ & $31.72 \%$ & $75.57 \%$ & $14.22 \%$ & $10.20 \%$ & $24.43 \%$ \\
\hline Canada & $35.36 \%$ & $26.76 \%$ & $62.13 \%$ & $22.00 \%$ & $15.87 \%$ & $37.87 \%$ \\
\hline NE ZEV States & $45.03 \%$ & $32.66 \%$ & $77.69 \%$ & $13.08 \%$ & $9.24 \%$ & $22.31 \%$ \\
\hline United States & $42.71 \%$ & $30.69 \%$ & $73.40 \%$ & $15.38 \%$ & $11.22 \%$ & $26.60 \%$ \\
\hline Focus Electric & $\mathbf{2 2 . 9 4 \%}$ & $\mathbf{1 7 . 0 5} \%$ & $39.99 \%$ & $34.76 \%$ & $\mathbf{2 5 . 2 5 \%}$ & $\mathbf{6 0 . 0 1 \%}$ \\
\hline California & $24.10 \%$ & $16.68 \%$ & $40.79 \%$ & $35.38 \%$ & $23.83 \%$ & $59.21 \%$ \\
\hline Canada & $13.85 \%$ & $11.35 \%$ & $25.20 \%$ & $39.85 \%$ & $34.95 \%$ & $74.80 \%$ \\
\hline NE ZEV States & $18.43 \%$ & $15.29 \%$ & $33.72 \%$ & $36.48 \%$ & $29.81 \%$ & $66.28 \%$ \\
\hline United States & $23.35 \%$ & $18.52 \%$ & $41.88 \%$ & $33.05 \%$ & $25.08 \%$ & $58.12 \%$ \\
\hline
\end{tabular}

The PHEVs are more apt to charge with a $120 \mathrm{~V}$ level 1 charger such as the mobile charger that comes with the vehicle which can charge a fully depleted battery in approximately 7 hours. This results in a slower charge time which is easily accomplished overnight while the owner is sleeping. A $240 \mathrm{~V}$ level 2 charger can complete the same charge in approximately 2.5 hours but it requires purchasing and installing the level 2 charger. PHEV owners are more likely to rely solely on level 1 charging, as this data suggests, with slightly over $70 \%$ of all charge events for PHEVs being done on level 1 .

BEV owners in comparison prefer to use a $240 \mathrm{~V}$ level 2 EVSE to charge their vehicle, with $60 \%$ of all charge events being completed on level 2. It is understandable that a BEV owner would be more likely to own a dedicated level 2 EVSE since the Ford Focus Electric vehicle could take as long as 20 hours for a full charge on level 1, but only 3.6 hours using a level 2 charger.

Canadian PHEV and BEV owners utilize more level 2 charging than their American counterparts and this is considered to be in part due to the investment in charging infrastructure. Canadians living in Ontario and Quebec can receive up to a $\$ 1,000$ rebate on the purchase and installation of a level 2 charging station, or $50 \%$ of the total cost [3]. In British Columbia the incentive increases to $\$ 4,500$ and $75 \%$ of the cost. The United States in comparison offers a 30\% federal tax credit up to $\$ 1,000$ on the purchase of an EVSE, with an assortment of local rebates available combined with programs from electric utilities to assist with installing residential EVSEs in some regions [4]. Future analysis will look at the variety of local programs in the United States which offer incentives for charging equipment and understand if this impacts charging behavior in the same ways Canadian charging is affected.

\section{Regional Comparison}

The previous sections have included information on the fleet which other studies such as the EV Project from Idaho National Laboratory have commented on in the past. It has been pointed out where Ford data corroborates with or differs from the information assembled in these studies for the various metrics outlined. 
The next section will provide deeper insight into regional data and how geographical differences translate into differing driver behavior. For our regional comparison we will continue to utilize our four geographic regions: Canada, California, the NE Zero Emission Vehicle (ZEV) mandate member states, and the United States excluding California and the NE ZEV states. These regions were selected because they offer insight into key differences found across national and state boundaries in which policy and external factors like electricity and fuel prices, charging infrastructure, and climate play a large role in shaping plug-in vehicle adoption and behavior. They also offer a large population of vehicles to evaluate.

Expanding on the policy factors, when speaking about California and the NE ZEV states it is important to note that these regions have adopted the ZEV mandate which requires sales of zero emission vehicles. Manufacturers comply with the ZEV mandate on an annual basis by meeting specific credit requirements for different vehicle categories that employ zero emission technology.

\subsection{Annual Mileage}

The annual mileage of a plug-in vehicle differs from that of a conventional gasoline vehicle. BEV owners have self-selected BEV ownership because of their confidence that the vehicle range will meet their needs or will modify their vehicle usage to adopt the new technology. PHEV owners on average drive further than a conventional gasoline vehicle, likely due in part to the increased fuel efficiency. Previous studies have shown that BEV owners drive significantly fewer miles annually than their conventional or PHEV counterparts unless accompanied by charging infrastructure, particularly workplace charging.

Table 6 Annual Mileage by Vehicle Model and Region

\begin{tabular}{|c|c|c|c|c|}
\hline & N & $\begin{array}{c}\text { Estimated } \\
\text { Annual } \\
\text { eVMT }\end{array}$ & $\begin{array}{c}\text { Estimated } \\
\text { Annual } \\
\text { VMT }\end{array}$ & eVMT \% \\
\hline C-MAX Energi & & & & \\
\hline California & 4,143 & 4,341 & 12,674 & $34.25 \%$ \\
\hline Canada & 782 & 3,491 & 10,295 & $33.91 \%$ \\
\hline NE ZEV States & 1,961 & 3,349 & 10,597 & $31.60 \%$ \\
\hline United States & 6,815 & 3,995 & 12,069 & $33.10 \%$ \\
\hline Fusion Energi & & & & \\
\hline California & 5,932 & 4,533 & 14,058 & $32.24 \%$ \\
\hline Canada & 537 & 3,852 & 11,284 & $34.14 \%$ \\
\hline NE ZEV States & 2,421 & 3,587 & 11,460 & $31.30 \%$ \\
\hline United States & 7,989 & 4,264 & 12,376 & $34.45 \%$ \\
\hline Focus Electric & & & & \\
\hline California & 2,328 & 8,796 & 8,796 & $100.00 \%$ \\
\hline Canada & 171 & 8,491 & 8,491 & $100.00 \%$ \\
\hline NE ZEV States & 339 & 8,030 & 8,030 & $100.00 \%$ \\
\hline United States & 1,826 & 8,251 & 8,251 & $100.00 \%$ \\
\hline
\end{tabular}

Table 6 above shows that vehicles perform differently in a variety of areas. California leads in BEV annual mileage perhaps due to more prevalent charging infrastructure, which Canada also benefits from due to large infrastructure deployment in major metropolitan areas as stated previously. The effects of the charging infrastructure can also be seen when analyzing the charging events per week for Canadian BEVs in the winter time, which average more than 10 charges per week as referenced in table 4 .

When analyzing PHEVs, key differences can be seen between the regions and the two models. C-MAX Energi tends to be driven less than Fusion Energi, as can be seen from the shorter average trip lengths and fewer miles per day (Table 2). In comparison, the Fusion Energi has higher annual eVMT and VMT (total miles travelled) distances than the C-MAX Energi. In areas of the United States outside of California and the NE ZEV states the differences between the PHEV models become less apparent.

PHEVs in cold weather areas of the Northeast ZEV states and Canada both experience reduced annual mileage and reduced eVMT compared to the other regions. However on a percentage basis Canada achieves more eVMT than the NE ZEV states with $34 \%$ compared to $31 \%$. California plug-ins travel further than any other region and achieve more eVMT.

For conventional gasoline vehicles, annual VMT in the United States is about 11,300 miles $(\sim 18,200 \mathrm{~km})$ while Canadian drivers average 9,530 miles $(15,336 \mathrm{~km})$ per year [5] [6] [7]. This shows that PHEVs in all 
regions travel farther than the average driver except for in the NE ZEV states, which have lower annual VMT than other PHEVs, while BEVs in all regions travel less than the average driver. The obvious restrictions of range account for a level of self-selection where customers with below average annual mileage likely have shorter commutes and choose the BEV knowing they can comfortably perform their daily activities without worrying about range restrictions.

\section{2 eVMT Differences}

\subsubsection{Charging Infrastructure}

Table 4 makes it apparent that all of the vehicles are charging on a regular basis, with a median of 7 to 8 charge events per week or roughly once per day. Canadian vehicles charge more often compared to other North American vehicles and this has apparent implications to eVMT achieved. For example, though Canadian BEVs only travel approximately 8,500 miles annually, this is equivalent to $90 \%$ of the typical Canadian drivers' annual mileage. In comparison, BEVs from the United States travel 8,250 miles annually, which only accounts for $73 \%$ of the typical mileage driven per year. It has been proven that charging more often equates to more eVMT and more annual mileage [1] and it appears Canadian regions are deploying and utilizing charging infrastructure more effectively than in the United States.

U.S. charging infrastructure data from PlugShare shows that the NE ZEV states at the end of 2015 had a total of 3,205 publicly accessible level 2 charging stations [8]. This translates to roughly 66 charging stations for every 1 million people, compared to Canadian infrastructure which has 78 charging stations per million people. Quebec, which registers more plug-in vehicle drivers than any other province in Canada, has 130 stations per million residents [9], which does not include the 110 volt access for block heaters, which are prevalent in colder cities in Canada. California has invested heavily in charging infrastructure (202 stations per million residents), the NE ZEV states will require more charging infrastructure in order to support their plug-in populations.

The EV Project demonstrated that BEVs and PHEVs both achieved significantly more eVMT when drivers are able to take advantage of public and workplace infrastructure. Those who charged away from home regularly achieved $72 \%$ more daily electric miles than those who did not [1]. Additionally the EV Project found that workplace charging accounted for approximately $32-39 \%$ of all charge events, with only 3-4\% of charging taking place at other public locations.

PHEVs were found to drive almost as many electric miles as BEVs, and with most of the charging away from home occurring at work, there is a great opportunity to increase eVMT for plug-ins by establishing more workplace charging. Workplace charging is even more affordable than other public charging infrastructure installations, representing greater potential to improve infrastructure access with limited incentive spending [10].

\subsubsection{Fuel and Electricity Prices}

Two other factors influencing eVMT are fuel and electricity prices, due to their ability to alter the desire to plug in. When gasoline prices are high there is more of an incentive to charge your vehicle. Similarly when electricity prices are high, there is less of an incentive to drive on electricity. Fuel and electricity prices can change with time, and across state, province, and national boundaries.

Studies have shown that drivers respond to fuel prices and will alter their driving behavior because of it, with some regions such as California, responding more in the short term than the nation as a whole [11]. UC Davis investigated populations of PHEVs and BEVs to better understand what encouraged people to plug in and they found that some plug-in owners specifically chose not to plug in due to the cost of electricity when compared to gasoline [12]. The study indicated that someone who does not see as much value in plugging in will do so less, and perhaps take less initiative in finding charging stations than someone who values plugging in more often.

Even in our own data we see behavior likely impacted by the cost of fuel and electricity. In table 2, Canadian Fusion Energi drivers travel nearly as far in the summer as California Fusion Energi drivers, 48.6 miles to 50.3 miles. Table 4 reveals that Canadians charge more per week than Californian Fusion Energi owners, 8.89 to 7.93 charges per week. Canadian Fusion Energi drivers travel almost the same distance as their California counterparts yet California has twice the installed charging infrastructure on a per capita basis, as indicated above, so what is the remaining factor? We believe the incentive to charge is stronger for 
Canadian Fusion Energi customers than for California customers, given the price comparisons between gasoline and electricity. For example, gasoline prices in March 2016 were \$3.02 USD per gallon in Quebec compared to \$2.39 in California [13] while electricity prices in Montreal were just \$0.06 USD per kWh compared to $\$ 0.21$ per $\mathrm{kWh}$ in San Francisco [14]. With electricity costing 1/3 the price in Montreal as it does in San Francisco, and gasoline costing 25\% more it is not surprising that Canadian Fusion Energi owners would charge more than owners in California. This information combined with the results UC Davis discovered on the impact of relative prices to charging behavior and the probability of finding public charging stations, leads to the conclusion that Canadian plug-in drivers are more apt to find and utilize the public charging infrastructure due to the greater price differential in their fuel choices.

\section{Conclusions}

In conclusion, the Ford fleet of PHEVs and BEVs exhibit average trip lengths within the vehicle battery range with BEV daily ranges well within the battery range and PHEVs having greater variability, demonstrating higher vehicle utilization especially for longer trips in the summer months. In general, EV mileage decreases in the winter consistent with conventional vehicle use with California being the only region with increased eVMT\% during that time. The data indicates that customers are selecting vehicles with attributes and functionality that are appropriate for their lifestyle. This analysis is consistent with the information found in the EV Project study.

Charging infrastructure, especially supplemental workplace charging infrastructure, could have a significant impact on total eVMT as demonstrated by the daily driving habits of Ford plug-in vehicles. Ford vehicles, and the electric vehicle industry as a whole, could benefit substantially from increased workplace charging given the number of miles that are driven daily by our vehicles. These insights provide an improved understanding of the electric driving needs of our customers.

Geographic location can have significant impact on charging and driving behavior, with individual factors including fuel prices, electricity prices, local charging infrastructure, and seasonal weather changes. The effects of each of these factors varies differently for PHEVs and BEVs, indicating that both products have strengths to offer in particular areas, with dependency on the region and landscape. The effects of cold weather, prevalence of long distance travel, type of housing, access to charging infrastructure and capacity for multiple vehicles are considerable factors which steer customers to a preferred electrification technology. Understanding these effects more thoroughly will help industry match the driving needs and wants of the electrified customer balanced with vehicle features and functionality to ultimately democratize electric propulsion to a broader base.

\section{References}

[1] The EV Project, "Plug-in Electric Vehicle and Infrastructure Analysis," September 2015. [Online]. Available: http://avt.inl.gov/pdf/arra/ARRAPEVnInfrastructureFinalReportHqltySept2015.pdf.

[2] R. S. S. R. Tim Triplett, "American Driving Survey: Methodology and Year One Results, May 2013 May 2014," AAA Foundation for Traffic Safety, Washington, DC, 2015.

[3] Electric Mobility Canada, "List of EVSE Incentives," March 2016. [Online]. Available: https://emcmec.ca/evse-101/list-evse-incentives/.

[4] U.S. Department of Energy, "Federal and State Laws and Incentives," March 2016. [Online]. Available: http://www.afdc.energy.gov/laws/.

[5] Federal Highway Administration, "Annual Vehicle Distance Traveled in Miles and Related Data," $\begin{array}{llll}\text { January } 2015 . & \text { [Online]. }\end{array}$ http://www.fhwa.dot.gov/policyinformation/statistics/2013/pdf/vm1.pdf. 
[6] American Public Transportation Association, "2014 Public Transportation Fact Book," Washington, 2014.

[7] Office of Energy Efficiency, "2008 Canadian Vehicle Survey Update Report," 610 2010. [Online]. Available: http://oee.nrcan.gc.ca/publications/statistics/cvs08/chapter2.cfm?attr=0.

[8] PlugShare, "PlugShare Quarterly - 2016-Q1 Census, US Electric Vehicle Infrastructure Exhibits," PlugShare, Venice, CA, 2016.

[9] ChargeHub, "Canada's Public EV Charging Stations Status," CHargeHub, 24 March 2016. [Online]. Available: http://chargehub.com/blog/en/canadas-public-ev-charging-stations-status. [Accessed 25 March 2016].

[10] The EV Project, "What were the Cost Drivers for Workplace Charging Installations?," May 2015. [Online]. Available: http://avt.inl.gov/pdf/EVProj/WhatWereTheCostDriversForWorkplaceInstallations.pdf.

[11] K. M. Hymel, "Factors Influencing Vehicle Miles Traveled in California: Measurement and Analysis," California State University, Northridge, 2014.

[12] M. A. N. J. D. J. W. Gil Tal, "Charging Behavior Impacts on Electric Vehicle Miles Traveled: Who is Not Plugging in?," Institute of Transportation Studies, University of California, Davis, Davis, 2013.

[13] U.S. Energy Information Administration, "Gasoline and Diesel Fuel Update," 21 March 2016. [Online]. Available: https://www.eia.gov/petroleum/gasdiesel/.

[14] Hydro Quebec, "Comparison of Electricity Prices in Major North American Cities," 1 April 2015. [Online]. Available: http://www.hydroquebec.com/publications/en/corporate-documents/comparaisonelectricity-prices.html.

Authors

Danny Boston started working full-time at Ford Motor Company in August 2014 after having completed a summer internship in 2013. During that time he has worked on home/vehicle energy modeling in support of the MyEnergi Lifestyle integration project, data analytics using electric vehicle customer utilization data from the MyFord Mobile app for policy and vehicle design development and several of the company's new mobility experiments highlighted in the Ford Consumer Electronic Show Keynote Address. Danny received his MS in Mechanical Engineering from Georgia Tech, where he worked in the Sustainable Design Laboratory, in part focused on Ford-sponsored projects, and his BS in Mechanical Engineering from the University of South Florida.

Alyssa Werthman is a principal environmental engineer at Ford Motor Company. During her fifteen year career at Ford, she has worked on a variety of environmental regulatory and compliance issues. For the past five years, her focus has been on policy work related to the U.S. fuel economy and greenhouse gas requirements and more recently, the California ZEV mandate. In her current role, she has studied plug-in electric vehicle driving behavior, consumer acceptance of ZEV technologies, and the impact of ZEV incentives to develop policy recommendations and to support strategic planning at Ford. Alyssa received her B.S. in Chemical Engineering from Carnegie Mellon University and an MBA and Masters in Manufacturing Engineering from the University of Michigan. 